\title{
Learning spaces around the university: Factors that affect the preferences for a space
}

\section{Lee, Jason Wen Yau}

${ }^{\mathrm{a}}$ Centre for Research and Development in Learning (CRADLE), Nanyang Technological University, Singapore

\begin{abstract}
A building space can play multiple roles within an education institution. New spaces are being designed and created with the hopes of fostering innovation, collaboration and creativity. The idea of developing such spaces can only be realised if there are sufficient resources but the fact is that many institutions simply will not have the resources to create such a change. Given that most universities have existing resources that were developed over the years, we propose a preliminary framework that can be used to evaluate existing learning spaces. The paper reports findings from a survey conducted with 2,842 students in a Singaporean university.
\end{abstract}

Keywords: learning spaces, evaluation, informal space 


\section{Introduction}

Education institutions are places where a community of scholars pursue knowledge, learning, and growth. The architecture of the institution expresses the institution's purpose, presence and domain in a physical form (Dober, 1996). However, Temple (2008) noted that the development of university spaces, new or old, does not include clues on how the learning spaces were conceived which makes the evaluation of learning spaces a challenge. Often, the pedagogical intent is not explicit in the mind of the designer, nor such evidence was easily available. Unless they are specially designed learning spaces (Painter et al., 2012) these spaces are rarely built with learning theories in mind. It is usually an afterthought for administrators and designers to consider evaluating the space although such evaluations are important to understanding how learning space are being utilised.

Like many other campuses around the world, the informal learning spaces evolved over time based on the needs of the users. Boys (2011) argues that one of there is an inherent tension between academics and estate planners, as space is becoming precious. Given that such upgrade requires a substantial amount of investment, there needs to be a clearer understanding of the factors that are important within the space. This paper is part of a larger study that aims to understand the factors that affect students' satisfaction of a learning space.

\section{Literature Review}

The evaluation of learning spaces is not just merely to measure how effectively the space is being used since the learning place can be described in terms of their social, cultural and architectural entity (Edwards, 2013). For example, utilising data based footfall and survey to establish demand and satisfaction would not paint a complete picture of how the space is being utilised as it fails to consider that learning is an activity (Bligh \& Pearshouse, 2011). In order to make a more convincing argument for the existence of a learning space, evaluations need to be grounded in theories of learning.

From a learner-centered perspective, learning can occur at any time through collaboration and socialisation. There is a small but growing interest in the field trying to understand how the physical environment affects teaching and the learning process. Studies in learning spaces can generally be categorised from the field of psychology and the field of architecture with many studies attempting to harmonise the fields through an interdisciplinary approach. From the field of psychology, researchers are interested in how people perceive the space and how learning occurs within the space while researchers from the field of architecture focused on how the facilities and infrastructure support learning. 


\subsection{Learning Theory}

Learning theory refers to the conceptual framework of understanding how knowledge is absorbed. Learning is no longer focused instructionism (Papert, 1993) where the goal was to get knowledge and procedures "transmitted" to students but rather shifting towards a constructivist approach where learning is a result of meaning making from the interaction with others. This means that learning is an active process and knowledge is created based on the social negotiation between the learners and their environment. The learning space, therefore, needs to provide the environment that will challenge the learner and their thinking.

Dugdale (2009) proposed the "learning landscape" as a holistic approach to understanding how a diverse landscape of learning (e.g., formal vs. informal, specialised vs. multipurpose, physical vs. virtual) setting affects student learning. There is a growing shift in examining learning spaces through a learner-centered approach where students, faculty, staff and the wider community can interact to promote a learning discourse. Learning is not just influenced by social factors but is, in fact, a social phenomenon (Rogoff, 1990). A learning space acts as a binding agent that provides the learner with the affordances to help with their meaning making process during the knowledge construction process.

\subsection{Architecture}

Architecture refers to the physical aspects of the learning space that is visible. This includes the physical building, design, furnishing and facilities within the space. The form and function of these spaces remain virtually unchanged within university campuses especially in formal learning spaces such as lecture theatres and classrooms. Such spaces are traditional and teacher-centered. This model functions well as students are not expected to be highly interactive during lectures nor are they expected to be doing so I had(Jamieson, 2003).

As we adopt a more student-centered approach to learning, designers and developers of spaces are looking at how spaces around campuses can be used to support learning. The assumption that merely building a space with the proper facilities makes it an effective or useful learning space is being replaced with a more holistic approach. A space only becomes a learning space when the affordances within the space (e.g., furniture and facilities) create an environment where knowledge and ideas can flow freely to support learning. 


\section{Method}

\subsection{Procedure}

The study was conducted at Nanyang Technological University, Singapore over a period of 9 months with a pilot study taking place in April 2016 upon gaining approval from the university's Institutional Review Board (IRB). A pilot study was conducted in September 2016 while the data for the study was collected at two points across Semester 1 for AY2016/2017.

The purpose of the pilot study was to understand how the various informal learning spaces around the university are being utilised by students. This was done by conducting an informal observation sweep which enabled the researchers to get a sense of the spaces available on campus. Based on existing literature and our research question, the research team piloted a survey questionnaire in 4 locations around campus. The survey captured anonymous student demographics, time and duration the space was utilised, and type of activities they were engaged. The open-ended questions captured the reasons students used a particular space and affordances that students thought were important to them.

The open-ended questions were categorised thematically, and the 10 most commonly coded themes were converted into "space satisfaction" statements that the respondents could state their level of agreement using a 4-point scale. The pilot survey questionnaire was refined to include both quantitative and open-ended responses and field notes were taken during the data collection. For the purpose of this paper, I will only discuss the space satisfaction section of the findings.

The first point of data collection was in September, which coincided with Week 3 of the semester while the second data collection was in November which coincided with Week 10 of the semester. These two data collection points were selected to understand if the dynamics of space changes across time. In total, 1,619 responses were collected in September, and 1,223 responses were collected in November.

\subsection{Data analysis}

The data collected were entered into IBM SPSS Statistics v23, a statistical tool for data analysis. An exploratory factor analysis (EFA) was performed on 2,842 respondents using principle components analysis with a Varimax and Kaiser normalisation resulting in three factors. The Kaiser-Meyer-Olkin measure of sampling adequacy was 0.74 , above the commonly recommended value of 0.6 , and Barlett's test of sphericity was significant ( $\left(\chi^{2}\right.$ $(45)=6855, \mathrm{p}<.05)$. Five items with a range between 0.580 to 0.801 loaded onto Factor 1 , three items with a range between 0.538 to 0.890 loaded onto Factor 2 and two items with a 
range of 0.752 to 0.830 loaded onto Factor 3 . There were no items in the data that was cross loaded.

\section{Findings}

This paper is part of a larger study that aims to understand how students utilise the various learning spaces around the university. However, to provide a context to the different learning spaces, we will discuss the spaces that were surveyed in this study which will be referred to as "managed" and "unmanaged" learning spaces.

Managed learning spaces are purposively built areas such as the library, study rooms and tutorial rooms that may be managed actively by a staff member during work hours. As the climate is hot and humid in Singapore, managed spaces are usually air-conditioned with facilities such as power sockets and specially designed tables and chairs that enable group or individual study. On the other hand, unmanaged spaces are transitional areas with tables and benches located within areas with high foot traffic such as outside the lecture halls, along the corridors or walkways between buildings, making it an ideal area to gather before class or in between classes.

The following sections will describe the three factors that affect the satisfaction of a learning space based on the EFA results.

\subsection{Factor 1 - Comfort}

The first factor that was loaded with five items is related to comfort. The term comfort in this study includes the way furniture is configured, air circulation, lighting, cleanliness and facilities (e.g., internet connection, power sockets) within the space.

Furniture configuration refers to the arrangement of tables and chairs within the space. The way the furniture is designed influences the way the space is being used and with learners expressing the desire for larger and more comfortable furniture (Harrop \& Turpin, 2013). The furniture in unmanaged spaces is intended to withstand the elements which are more durable and hence less comfortable. On the other hand, the furniture in most of the managed spaces is slightly movable, reconfigurable with proper chairs and tables designed for studying.

Air circulation refers to the air quality and environment of a learning space. The research site is located in a hot and humid country with an average temperature of $27^{\circ} \mathrm{C}$ but is surrounded by a large green space. Air-conditioning is a norm in most of the spaces especially in the managed areas, but not all students enjoy the air-conditioning as the temperature may be too cold especially if they are in the area for long hours. Some students 
responded that they preferred the natural outdoor breeze despite the warm and humid conditions.

Lighting refers to how much light is in a space, and plays an important role especially when the spaces are used for studying. Learners describe that lighting and natural light was an important factor when using a space (Harrop \& Turpin, 2013). In this study, unmanaged spaces were located in areas that have natural lighting but required additional lighting in the later part of the day. Managed spaces are usually located within buildings which require additional lighting throughout the day to illuminate the space thus makes it well lit.

Cleanliness is part of the routine building management and upkeep of a space. In general, most of the spaces surveyed had high satisfaction in terms of cleanliness, but unmanaged spaces have slightly lower levels of satisfaction. This can be attributed to the fact that these areas are not fully sheltered and exposed to the elements which may affect their overall perception of cleanliness.

Facilities such as projectors, power sockets, and WiFi is becoming a norm in learning spaces. This study found many students using the space with laptops or their mobile devices. Therefore, the availability of power sockets was very important to students and spaces that did not have ample power sockets had a poorer satisfaction rate on their facilities.

In short, the "comfort" of a space is largely dependent on the location. For example, spaces located in an enclosed area such as the library or specially designed tutorial rooms is rated higher in comfort as compared with spaces such as foyers and walkways outside the lecture theatres which are not enclosed or air-conditioned. Areas that scored high on comfort are usually air-conditioned with furniture that can be slightly reconfigured such as movable chairs or tables that enable group discussion.

\subsection{Factor 2 - Convenience}

The second factor that was loaded with three items is called "convenience" which relates to proximity to classes, the restrictions on eating in a space (food restriction), and the ability to hold discussions. We found that the convenience of a space is highly related to whether the areas is located along the walkways outside the lecture theatres or areas that are on the way to the bus stop.

The proximity of a space to classes or along main walkways on campus was one of the factors that influences students' preference on a space. For example, learning spaces outside the lecture theatres were convenient for students to meet up with others for group meeting or group study. However, this study found that students were willing to move around to different learning spaces around campus to their preferred learning space if it is not too far away from their own faculty. 
There is a debate especially within the librarianship community (e.g., Bedwell \& Banks, 2013) whether or not to allow food to be consumed in learning spaces. Most students in this study spend between 1-4 hours in each space. The ability to consume food and drinks would mean that students would be able to stay in the location for longer periods without having to move and stay focused longer (O’Connor, 2005). In this study, unmanaged spaces usually have no restrictions regarding the consumption of food but managed spaces such as the library may have restrictions in the type of food that may be consumed.

Depending on how students use a learning space, the ability to have discussions was also important. For example, students who are looking to study individually would prefer the library quiet zones while students having group discussions may opt to go to areas where there are open spaces and larger tables.

\subsection{Factor 3 - Community}

The third factor that was loaded with two items is related to community. Community in this study is defined as spaces that provides privacy and spaces where meetings are regularly held.

In this study, privacy encompasses two different meanings: privacy for individual study and privacy for collaborative work. For individual study, privacy would mean that the space is free from distractions such as heavy foot traffic or away from noise such as in the library quiet zones. On the other hand, privacy for students engaging in group meetings or group study would mean that the space allows for group work and discussion without being overly distracting to others.

Learning spaces are also areas where students gather to meet for both study and relaxation (Harrop \& Turpin, 2013). From the qualitative data observation, we found that most students were working in close proximity to friends or peers although they may not be collaborating with each other all the time. The idea of working together was also observed by other researchers such as O'Connor (2005) who termed it as "studying along". This means that groups of students who are sitting together on the same table may not be necessarily studying the same materials but rather enjoy having the company of others who are performing the same task. 


\section{Conclusion}

This paper discusses findings from a study that intends to understand how students were using learning spaces around the campus. Using a ground up approach, we identified three factors that can describe the satisfaction of a space which are comfort, convenience and community. This study found that the affordances within the space, and the location of the space plays an important role to the overall satisfaction. Although not discussed in this paper, the purpose of the using the space (e.g., individual study, group meetings, etc.) plays an important role towards the general satisfaction of the space. The next step of the study is to built a space typology by incorporating both the quantitative data from the survey and qualitative data (field notes and focus group discussions).

As space is a precious commodity for campuses around the world, this paper provides a framework for evaluating learning spaces for both administrators and space planners. Given that there can be infinite combinations of preferences, spaces can be designed and configured to meet the needs of students. More purposeful placing and design furniture and facilities changes the way the space is perceived and how the space is being used.

\section{References}

Bedwell, L., \& Banks, C. (2013). Seeing through the eyes of students: Participant observation in an academic library. Partnership: The Canadian Journal of Library and Information Practice and Research, 8(1).

Bligh, B., \& Pearshouse, I. (2011). Doing learning space evaluations. Re-shaping learning: A critical reader: SensePublishers.

Boys, J. (2011). Towards creative learning spaces: Re-thinking the architecture of postcompulsory education. NY:US: Routledge.

Dober, R. P. (1996). Campus Planning: Renhold.

Dugdale, S. (2009). Space strategies for the new learning landscape. Educause Review, March/April, 51-63.

Edwards, B. (2013). University architecture. NY: Routledge.

Harrop, D., \& Turpin, B. (2013). A study exploring learners' informal learning space behaviors, attitudes, and preferences. New Review of Academic Librarianship, 19(1), 58-77. doi:10.1080/13614533.2013.740961

Jamieson, P. (2003). Designing more effective on-campus teaching and learning spaces: a role for academic developers. International Journal for Academic Development, 8(1-2), 119-133. doi:10.1080/1360144042000277991

O'Connor, R. A. (2005). Seeing DuPont within Sewanee and student life. Task Force Final Report for the Jessee Ball duPont Library. 
Painter, S., Fournier, J., Grape, C., Grummon, P., Morelli, J., Whitmer, S., \& Cevetello, J. (2012). Research on learning space design: Present state, future directions. Retrieved from https://www.uwsuper.edu/facilities/upload/ResearchOnLearningSpaceDesign.pdf

Papert, S. (1993). The children's machine: Rethinking school in the age of the computer. NY: Basic Books.

Rogoff, B. (1990). Apprenticeship in thinking : cognitive development in social context. New York: Oxford University Press.

Temple, P. (2008). Learning spaces in higher education: An under-researched topic. London Review of Education, 6(3), 229-241. doi:10.1080/14748460802489363 